\title{
A multisource approach for coastline mapping and identification of shoreline changes
}

\author{
Annibale Guariglia, Arcangela Buonamassa, Angela Losurdo, Rocco Saladino, \\ Maria Lucia Trivigno, Angelo Zaccagnino and Antonio Colangelo \\ GEOCART srl, Potenza, Italy
}

\begin{abstract}
Coastal dynamics are driven by phenomena of exogenous and endogenous nature. Characterizing factors that influence their equilibrium and continuous monitoring are fundamental for effective environmental planning and management of coastal areas. In order to monitor shoreline changes, we developed a methodology based on a multisource and multitemporal approach. A database, related to the Ionian coast of Basilicata region (about 50 $\mathrm{km}$ ), was implemented by using cartographic data (IGMI data), satellite imagery (SPOT-PX/XS, Landsat-TM, Corona) and aerial data covering the period form 1949 to 2001. In particular, airborne data (1 m spatial resolution) were acquired during a specific campaign we performed in 2000 and 2001. To obtain the best performance from the available data, we applied a data fusion procedure on visible and thermal information. Different algorithms were tested, such as band ratios and clustering for extracting the coastline. The best results from multispectral data were obtained using a threshold algorithm we devised by exploiting the green, red and NIR bands, whereas for panchromatic data we selected clustering as the more suitable method. Moreover, a GPS survey was performed to evaluate the influence of tidal effects.
\end{abstract}

Key words coastline mapping - satellite - GPS tide - multitemporal analysis

\section{Introduction}

The coastline is defined as the boundary between land and a water surface. It is the most dynamic part of seascape since its shape is affected by different factors, such as hydrography, geology, climate, and vegetation. All these factors contribute to change the coastline shape in a dynamic equilibrium. In addition to natural phenomena, anthropic activities have a crucial role in modify-

Mailing address: Dr. Annibale Guariglia, GEOCART srl, V.le del Basento 120, 85100 Potenza, Italy; e-mail: a.guariglia@geocart.net ing such an equilibrium. Therefore, a continuous update of coastal maps is needed to understand the driving factors and to provide relevant information for coastal resource management and environmental protection and for planning sustainable development of coastal areas.

Traditional methods for coastline mapping are based on conventional field surveys or on the interpretation of aerial photographs. Usually, the rectified aerial photographs are manually interpreted using analytical stereo-plotting equipment (see, e.g., Lillesand and Kiefer, 1987). Periodic over-flights and aerial photograph analyses imply a high cost for updating coastlines. In such a context, image processing on satellite remote sensing data can provide a suitable tool for updating coastal maps over large areas at relatively low costs (Cracknell, 1999; Nayak, 2000). Moreover, the high repetition rate of images acquired from space can provide the appropriate temporal 
sampling for studying the highly dynamic phenomena that determine the coastline shape.

In recent years, satellite remote sensing data has been used in automatic or semiautomatic coastline identification. In particular, much work exploited Landsat TM (Thematic Mapper) data by applying different analysis techniques. A simple density slicing method applied to SWIR bands: TM channel 5 has proved to be useful in clear water conditions (Braud and Feng, 1998; Fraizer and Page, 2000); whereas Kevin and El Asmar (1999) found the use of TM channel 7 more suitable for monitoring changes in coastline position.

Other work was based on supervised and unsupervised classifications of multispectral data such as TM or Spot (Baban, 1997; Erkkila and Kalliola, 2004; Ustun et al., 2004). Siddiqui and Maajid (2004) evaluated a multitemporal PCA (Principal Component Analysis) on Landsat MSS and TM data to evaluate coastal changes between 1973 and 1998 in Pakistan. Other studies exploited a combined approach of single band thresholds and NDVI (Normalized Difference Vegetation Index) (Ryu et al., 2002) and found this approach very useful for tidal flat areas.

Such an outline reveals that a large number of methods are available for mapping coastline from different sensors.
The aim of this work is to evaluate of different techniques for analyzing a multisource dataset in the context of coastline change studies.

\section{Study area}

The study was performed on the Ionian coastal area in Basilicata Region (Southern Italy) (fig. 1). The mouths of principal rivers of the region (Bradano, Basento, Cavone, Agri, and Sinni) are located along this coast (about $50 \mathrm{~km}$ ). The Ionian coast is a flat beach of fine sandy formations. In particular, the coast between the Bradano and Basento river mouths is characterized by a narrow shore $(10-35 \mathrm{~m})$ and, inland, by wetland zones; whereas the shore between the Cavone and Basento river mouths is extended up to $300 \mathrm{~m}$.

Several studies (see, e.g., Mastronuzzi, 1996; Marsicano and Trevisani, 1996; Bonora et al., 2002) were performed on the evolution of the Ionian coast; their results can be summarized as follows:

- Between 1873 and 1949/1954 they found a shore progression ranging between 0.7 and $5.5 \mathrm{~m} /$ year, the highest values mainly located in the river mouths.

- After 1950 they found an inverse process, a remarkable shore regression took place; par-

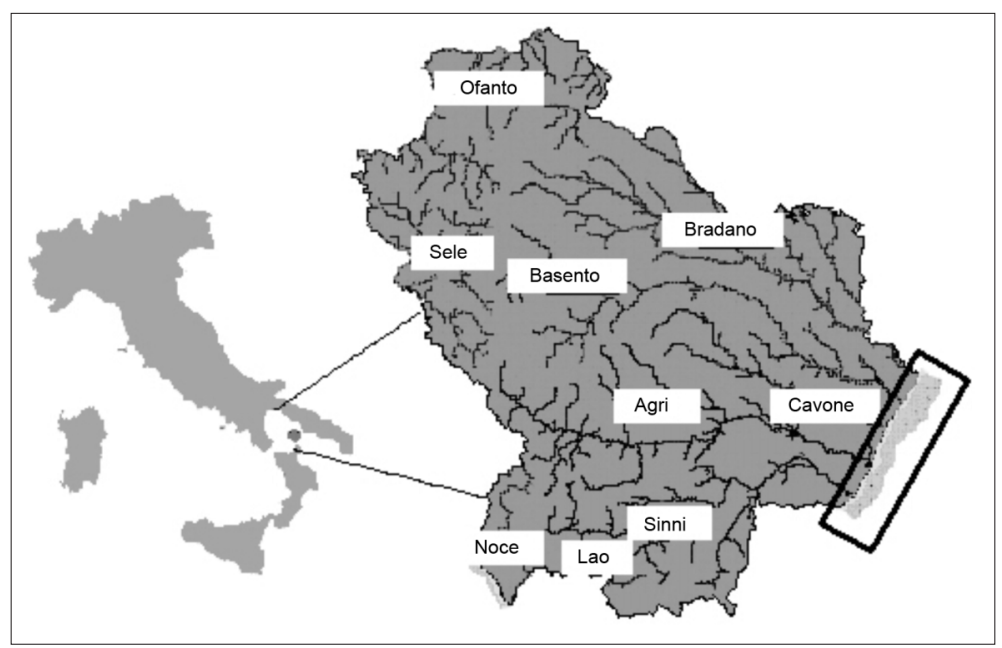

Fig. 1. Study area: Ionian coast of Basilicata Region (area highlighted by the black rectangle). 
ticularly, between the Bradano and Basento rivers the coastline retreated about $2.3 \mathrm{~m}$ per year during the period 1944-1954 and about 0.7 $\mathrm{m} /$ year from 1954 to1965, finally a retreat of 4 $\mathrm{m} /$ year is recorded since 1965 .

They conclude that, in the last fifty years, the shore erosion has been mainly caused by a reduction of fluvial sediment supply due to the effect of dam constructions on the principal rivers of the region. In such conditions the coastal environment is based on a finite sediment volume and therefore intervention activities are needed and must consider the complexity of both coastal and basin ecosystems.

\section{Materials and method}

Since the coastline is the line of contact between sea and land, as the sea level varies, this boundary varies and therefore it is difficult to exactly identify its position. Variations in coastline position can be: long-term, cyclical, random, due to specific events.

Long-term variations are due to sand storing processes along the coast or due to relative sea level rising; such changes are modeled by the presence of creeks and headlands. Cyclical variations refer to coastal width and shape changes that are linked to the seasonality or tidal conditions. Random variations mainly have a local character since they are caused by wave conditions, storms or floods; therefore, the coastline can change locally in a very short time period.

Coastline mapping depends on measurement methods (strictly linked to aims) as well as on data accuracy that is linked to spatiotemporal scales and to the selected instruments.

\subsection{Tidal data and their influence on determining the coastline}

Among the cyclical variations, tides cause rapid sea level variations; therefore, it is fundamental to evaluate such effects during the image acquisitions to locate the free-surface level. Tides are due to astronomic and meteorological phenomena. In particular, the astronomic tide is due to the gravitational attraction of sun and moon (30\% and $70 \%$ respectively). It is evaluated by applying the so called harmonic method, that considers the sum of tidal components represented by sinusoidal waves: seven components (four semi-diurnal and three diurnal) are enough to have an approximation of one centimeter (NOAA, 1982).

Since the selected images were acquired in good weather conditions (calm sea), we neglected the influence of meteorological tide.

Tide conditions for our dataset (see Section 3.2) were evaluated using the freeware wxtide 32 programme (http://www.wxtide32.com/).

For the area of interest, the oscillations of water level (only due to astronomic tide) range between 20 and $45 \mathrm{~cm}$ in a semi-diurnal behavior (oscillation time of about $12 \mathrm{~h}$ and $25 \mathrm{~min}$ ) characterized by two maxima and two minima that are not coincident. The induced water level variations cause different variations in coastline position depending on coastal morphology. Taking into account the maximum water level increase $(45 \mathrm{~cm})$ and coastal slopes (measured by GPS survey, see the following section), the maximum shift in coastline position is about $5 \mathrm{~m}$.

According to this result, it is clear that satellite images are affected by tidal variations depending on their spatial resolution. Therefore, we can extract the coastline from Landsat TM images (having a spatial resolution of $30 \mathrm{~m}$ ) without the interference of the tidal factor. On the contrary, tidal effects must be considered when the coastline is identified from images having higher spatial resolution that are comparable to the errors induced by tide.

\subsection{Dataset}

In order to perform a multitemporal analysis of coastline variations for the Ionian coast, we implemented a database made up of data from different sources and at different spatial resolutions covering the period from 1949 to 2001. The used data are reported in the following list:

- IGMI (Istituto Geografico Militare Italiano) Cartography, scale 1:25000, 1949;

- Orthophotos (B/W), scale 1:10000, 1997;

- Airborne images (Visible), resolution $1 \mathrm{~m}$, 2000 and 2001; 
- Airborne images (Infrared), resolution 3m, 2000 and 2001;

- Landsat5 TM, resolution 30 m, 19/05/1984, 18/07/1994, and 13/07/1998;

- Landsat7 ETM+, resolution $30 \mathrm{~m}$, 26/09/1999, and 30/08/2001;

- Spot XS, XI, PX, resolution 20 and $10 \mathrm{~m}$, 19/02/1998, 31/05/1998, and 25/08/1998;

- Corona Pan, resolution 7.62 m, 12/09/1961;

- GPS data, 2000 and 2001.

The IGMI cartography (the oldest data, 1949) was selected as reference information to estimate coastline changes.

The airborne images were acquired by Geocart from five overflights covering a one year period between 2000 and 2001 in order to evaluate the coastline seasonal cycle. The visible images were acquired using a $6 \times 6$ metric camera (Rolleimetric 6008), whereas for the infrared images, we used a thermal camera hav- ing a band range between 3 to $5 \mathrm{~nm}$ and CCD resolution of 270000 pixels.

The GPS survey was carried out for several reasons: i) to map the coastline; ii) to map the cross sections of shore slopes; iii) to verify the reliability of the airborne image georeferencing; and finally, iv) to create a reference network for future surveys.

The geometric location of the GPS survey was obtained by using the new satellite geodetic network, IGM95. After a careful analysis of the places and the identification of the reference vertexes, we thickened the network around such vertexes in order to perform the measurements for the cross sections (transects perpendicular to the coastline).

The cross section measurements were acquired in calm sea conditions in order to simplify the identification of the water/land boundary line (fig. 2). The derived coastal slopes are im-

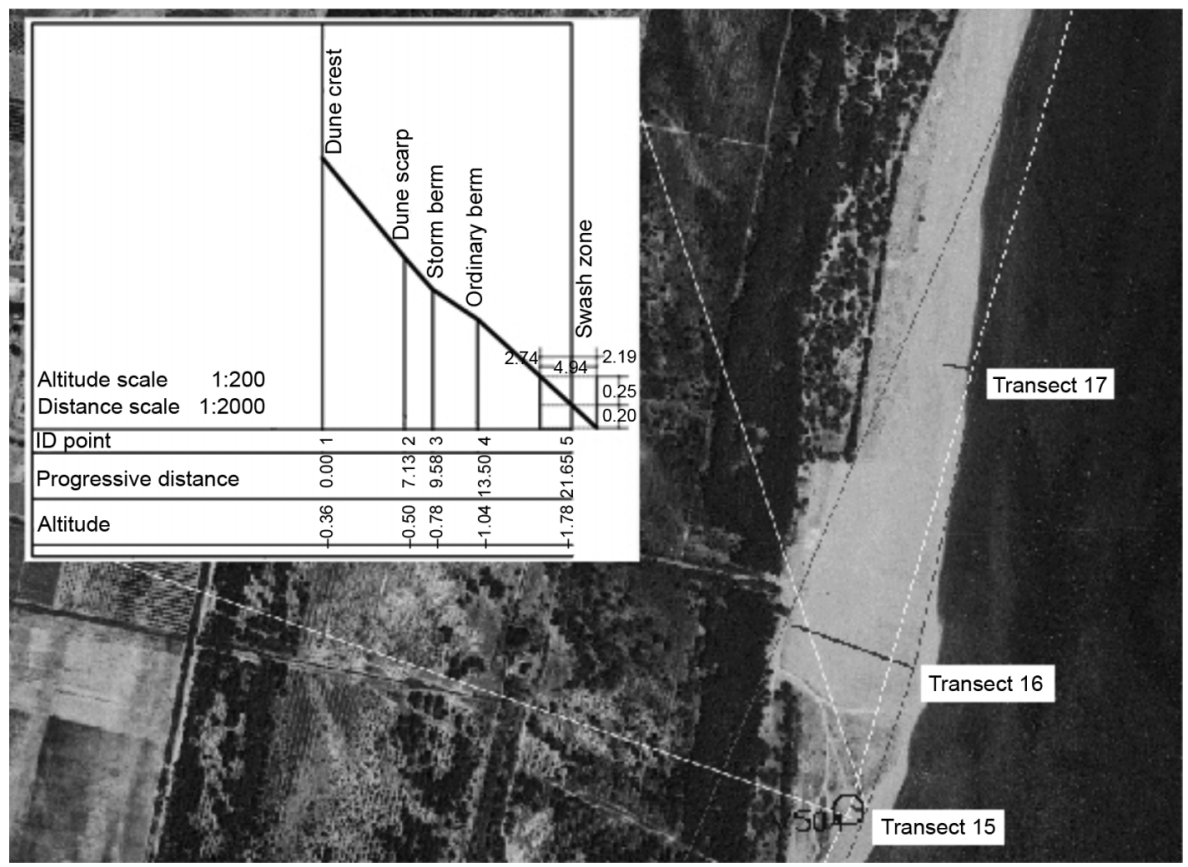

Fig. 2. Example of shore slope measured by GPS for a transect. The foreground figure shows the different transitional points for each shore feature (dune crest, storm berm, etc.) along transect 15 (shown in the background image). 
portant for determining the area influenced by the tide for each transect.

A crucial point in performing multitemporal analysis is a precise image overlay, particularly from a multisource dataset. All the images were geometrically corrected according to UTM projection on ED50. Many unchanged features were identified on the IGMI map, compared with GPS data and rectified when it was necessary. Then, all the images were georeferenced on this map by using a number of GCPs proportional to image dimension and resolution. Overlap errors were evaluated on single GCP and on polygonal features, such as roads, railways, etc. Then, linear fits were performed on the selected polygons in order to evaluate the discrepancy. The goodness of such fits $(R=0.9992)$ demonstrates the reliability of the dataset overlays.

\subsection{Coastline mapping procedures}

The available images of the Ionian coast have different spectral and spatial resolutions. Therefore, the coastal characteristics that can be highlighted from the data are different as well as it is different the accuracy of coastline positioning. In particular, for satellite data there is the intrinsic error due to the pixel size (spatial resolution).

From a pre-analysis of orthophotos and airborne images acquired from our flights, we have deduced that it is quite difficult to locate the highest swash zone line by using photo-interpretation, whereas we could easily locate the water line, the shore dry/wet line and the shore/vegetation line. For Spot, Landsat and Corona data, the identifiable characteristics are the shore/sea line and the shore/dune line.

The dataset was analyzed by applying two different procedures: band ratios on multispectral data and unsupervised classification on multispectral and panchromatic data. The flowchart of such procedures is shown in fig. 3 .

\subsubsection{Band ratio from multispectral images}

The method based on multispectral images exploits the NIR and SWIR bands. Such wavelengths are highly absorbed by water, and there-

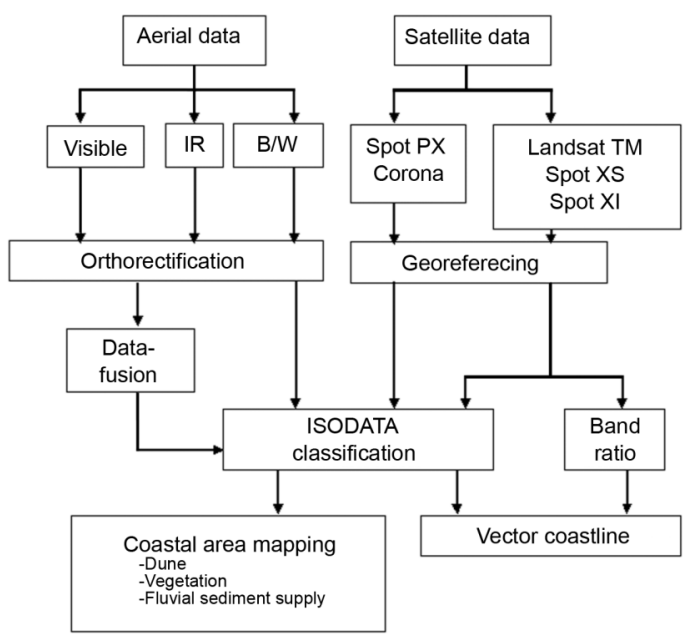

Fig. 3. Flowchart of the approach applied for coastline identification from the different data sources.

fore surface water appears black on imagery. These spectral bands also exhibit higher reflectance characteristics from soil and healthy vegetation, providing a context for the land/water interface (see, e.g., Braud and Feng, 1998; Fraizer and Page, 2000). Moreover, in order to enhance the shore/sea contrast we added information from VIS bands. Band selections were based on a spectral analysis performed on different transects. Figure 4 shows the different spectral responses for the selected bands from Landsat TM and Spot XS data.

Coastline identification from Landsat and Spot data was obtained by applying the following algorithms:

$$
\text { if } \mathrm{B} 5 / \mathrm{B} 2<1 \text { then } 255 \text { else } 0
$$

for Landsat TM and ETM+ images where B5 $(1.55-1.75 \mu \mathrm{m})$ and B2 $(0.52-00.60 \mu \mathrm{m})$.

$$
\text { If } \mathrm{B} 3 /(\mathrm{B} 1-\mathrm{B} 2)<1 \text { then } 255 \text { else } 0
$$

for Spot XS and XI images where B1 (0.50$-0.59 \mu \mathrm{m}), \mathrm{B} 2(0.61-0.68 \mu \mathrm{m})$ and B3 $(0.79-$ $-0.89 \mu \mathrm{m})$.

From the application of these algorithms we obtained a bitonal image that is particularly 

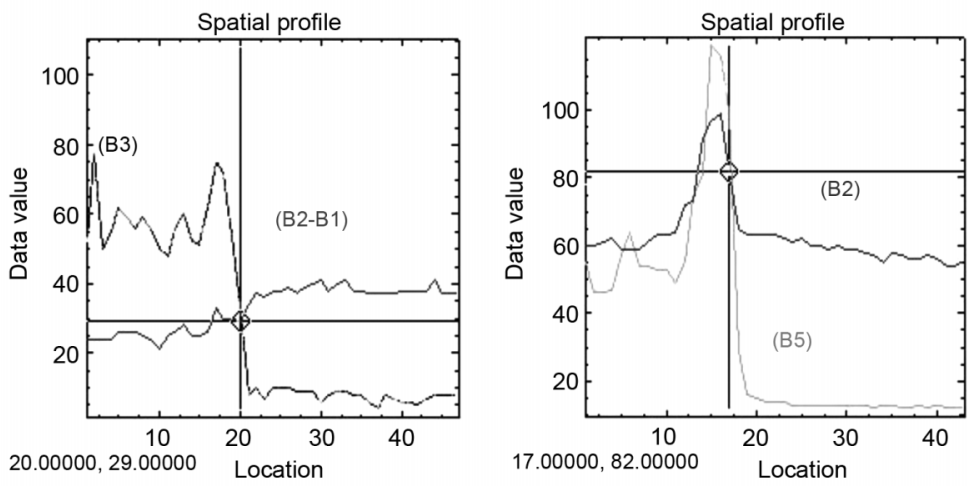

Fig. 4. Spectral signatures of the channels used for the band ratio procedure: Spot (left) and Landsat (right). The signature are related to a transect from the shore (left side of each diagram) to the sea (right side). The intersection enhanced by a circle represents the water boundary.

useful for an automatic extraction of coastline vector information. After the raster to vector conversion we evaluated the conversion accuracy by overlaying the obtained coastline with the original image.

\subsubsection{Unsupervised classification}

Unsupervised classification of land cover has been successfully used for many applications involving thematic mapping with an accuracy of about $80 \%$ for most land cover types. The accuracy drops, however, in highly complex ecosystems and wetland environments (see, e.g., Adams et al., 1995; San Miguel-Ayanz and Biging, 1997; Millington et al., 2001).

The unsupervised Iterative Self Organized Data Analysis (ISODATA) clustering algorithm is commonly used for classification of complex areas and is a highly successful semi-automated process.

The main parameters of the ISODATA algorithm are:

- $k$ number of clusters;

- $n_{m}$ minimum number of samples for each cluster;

- $\sigma_{s}$ standard deviation of samples from the center (cluster separation);

- $\theta$ shading (fusion);

- $l$ max number of cluster which can melt together in one iteration;
- $i_{\max }$ max number of iterations;

- $n_{c}$ centres of initial clusters.

We applied the clustering procedure on different data; in particular, we classified the IGMI orthophotos, aerial images, Spot PX data and Landsat multispectral data.

For multispectral data, ISODATA clustering was run on TM Bands 7, 5 and 4 for a better land/water discrimination; then, clusters related to land and water were collapsed.

For the airborne images, we applied a data fusion technique on visible and thermal data before the classification procedure in order to obtain the best information. Since the infrared acquisitions ( $3 \mathrm{~m}$ resolution) from the thermal camera depend on surface temperature and humidity such data enables us to have information on the boundary between dry-wet shores. The metric camera acquisitions in the visible provide us information at higher spatial resolution $(1 \mathrm{~m})$ on different land covers. The data fusion was obtained by applying the so-called image sharpened technique. The images at low resolution were resampled to the pixel size of those having a high spatial resolution and were transformed from the Red-Green-Blue (RGB) domain to the Hue-Saturation-Value (HSV) domain. In the HSV range, the Value band was substituted with the high resolution image in gray levels. Finally, we re-transformed the bands from the HSV domain to the RGB domain. The result of this process is a three-band image that combines the 
high spatial resolution from visible data with spectral information from thermal data. We applied such a procedure on all the acquired images and then, the transformed images were classified by using the ISODATA classification.

IGMI orthophotos and Spot PX image were directly classified as a gray level image.

\section{Results and discussion}

Good results were obtained from the application of band ratios, fig. 5 shows an example for Spot XS and Landsat ETM+ data. The sea/land boundary obtained was tested by comparison with the digitalized coastline for the old
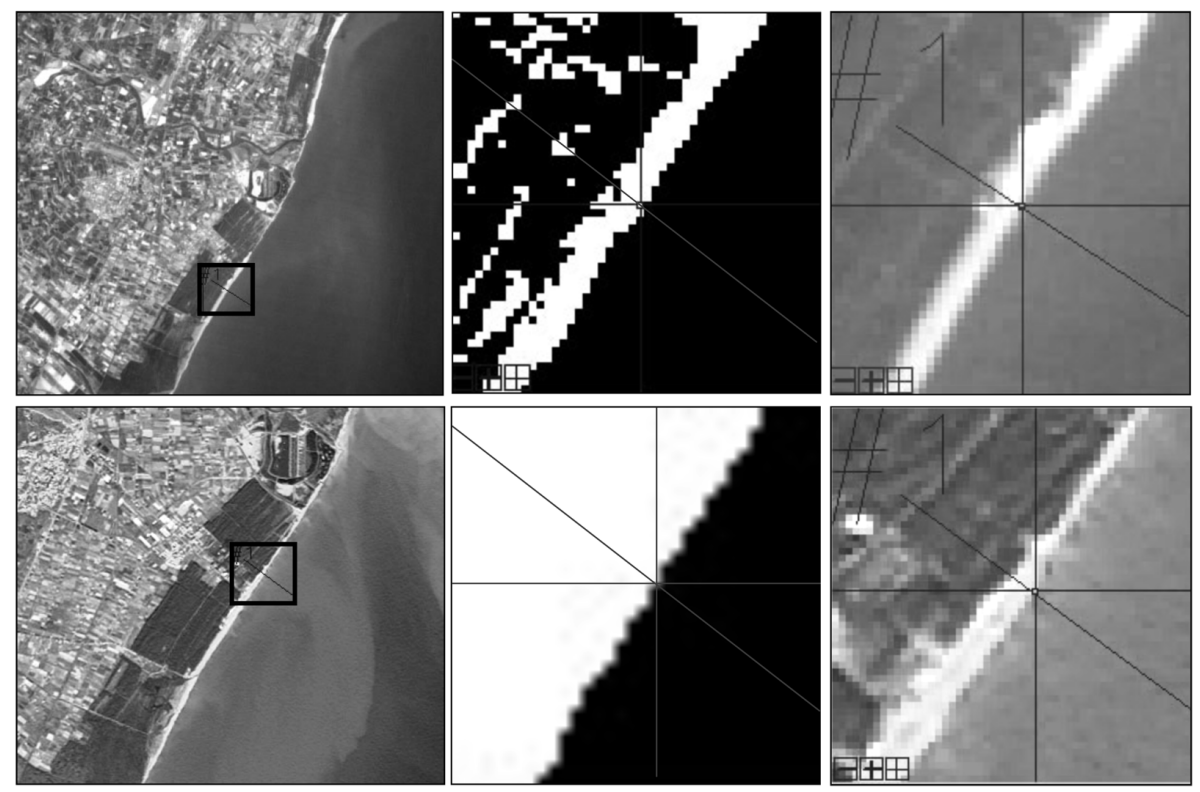

Fig. 5. Example of results obtained by applying band ratios for Landsat (top) and Spot (bottom). The central and right images are the obtained bitmaps and zooms of the areas inside rectangles (the left images) respectively.
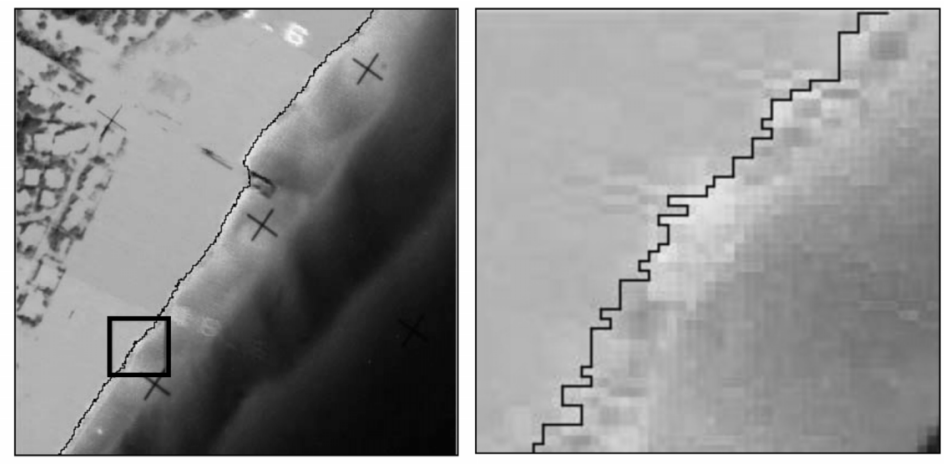

Fig. 6. Example of coastline obtained from ISODATA clustering on merged aerial photos. The larger image (left) and the zoomed area inside rectangle (right) show the coastline overlapped on the merged photo. 
imagery, whereas the ETM+ image (acquired in 2001) was verified by comparison with GPS data. The sea/land boundary obtained from satellite image perfectly overlaps the coastline obtained from GPS surveys.

An example of coastline identified by using ISODATA on merged aerial photos is shown in fig. 6 . The image on the left also shows the seabed slopes.
Concerning the band ratios, such a procedure can be only applied to multispectral data from sensors acquiring radiances in the specific spectral bands; its main peculiarities are: ease of application, low time consumption, and the absence of operator intervention.

On the contrary, the ISODATA classification requires long data processing depending on the analyzed image (dimension and spatial res-

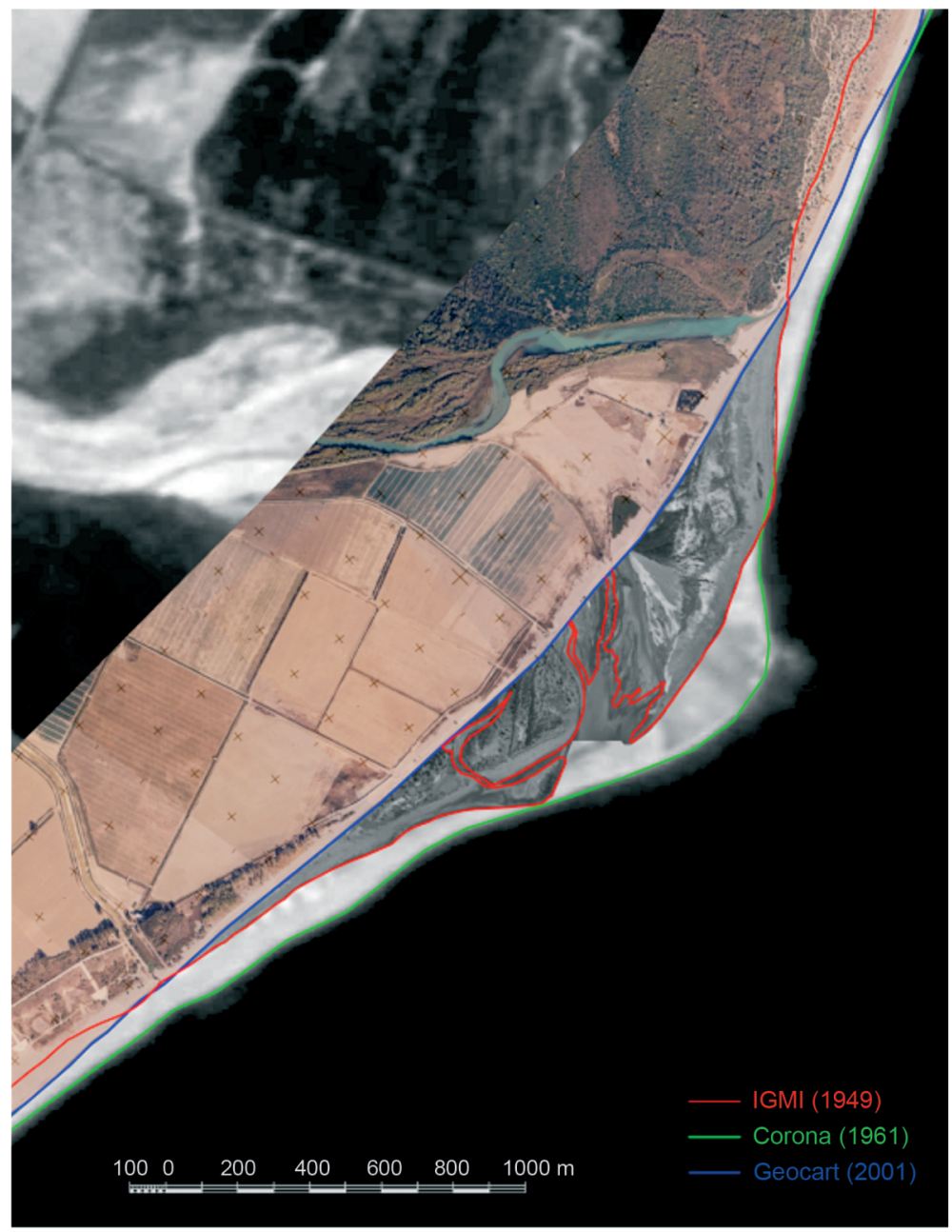

Fig. 7. Coastline evolution for the area of the Sinni River mouth from 1949 to 2001 . The comparison between IGMI (1949) and Corona (1961) data shows a coastline accretion of about $160 \mathrm{~m}$, whereas an erosional process (retract of about $500 \mathrm{~m}$ ) is enhanced between Corona and aerial photos (2001) coastlines. 
olution) and on the selected parameters, such as threshold levels. Moreover, it needs an operator for feature/cluster interpretations. An advantage in using ISODATA is the possibility of identifying further shore characteristics, such as dry shore, wet shore, dunes, fluvial sediments, and vegetation. Such additional classification could be very useful for studies on shore ecosystem or for planning intervention activities.

Multitemporal comparison of coastlines obtained from our dataset showed different progression and regression trends. On average the shore area has decreased by about $265000 \mathrm{~m}^{2}$ from 1949 to 2001. Results confirmed that an erosion process is ongoing mainly near the river mouths. This is particularly evident near the Sinni River as shown in fig. 7, where the overlap of coastline obtained from IGMI data, Corona and aerial images is reported. We can note a coastline accretion ( $160 \mathrm{~m}$ ) from 1949 to 1961 and progressive coastal erosion from 1961 to 2001 of about $500 \mathrm{~m}$.

The principal cause of such a regression in recent years is a continuous reduction of fluvial sediment supply. In particular, the Sinni River supply is affected by the presence of one of the largest Earth dams in Europe (capacity 630 $\mathrm{Mm}^{3}$ ), it was reduced by about $95 \%$ after the dam construction (ISMES, 1987; Spilotro et al., 1999).

\section{Conclusions}

The aim of this work was to identify a reliable methodology based on multisource data for mapping coastline changes. Results seem encouraging since the extracted coastline fits well with the real coastline. In particular, results from the analyses on panchromatic images showed that unsupervised classification is a suitable approach for elaborating such data since this procedure required reduced time compared to the classical digitalization method.

For multispectral data, we selected the band ratios as the best technique for mapping the coastline in a sandy environment mainly because it allows for obtaining the same precision of classification results, but it is easier to apply and less time consuming. Further tests are needed to evaluate the band ratio accuracy in rocky and vegetated coats.

Another major consideration is related to tidal effects: the evaluation of tide variations is mandatory for studying changes in the coastline from high spatial resolution data, such as from IKONOS, Quickbird or from the upcoming Cosmo SkyMed constellation.

The applied approach represents a basic step to obtain a reliable tool in controlling and monitoring coastline variations from a heterogeneous dataset.

\section{Acknowledgements}

This work was supported by ASI in the framework of «Cosmo SkyMed per il monitoraggio dell'evoluzione dei litorali: analisi multitemporale della costa Ionica della Basilicata» project (C. I/208/00/0). The authors are grateful to the anonymous referees for the suggestions made in improving the manuscript.

\section{REFERENCES}

Adams, J.B., D. Sabol, V. Kapos, R. Almeida Filho, D.A. Roberts, M.O. SMith and A.R. Gillespie (1995): Classification of multispectral images based on fractions of endmembers: Application to land-cover change in the Brazilian Amazon, Remote Sensing Environ., 52, 137-154.

BABAN, S.J. (1997): Environmental monitoring of estuaries; estimating and mapping various environmental indicators in Breydon Water Estuary, U.K., using Landsat TM imagery, Estuarine Coastal Shelf Sci., 44, 589598.

Bonora, N., F. Immordino, C. SchiaVi, U. Simeoni and E. VALPREDA (2002): Interaction between Catchment Basin Management and Coastal Evolution (Southern Italy), J. Coastal Res., 36, 81-88.

Braud, D.H. and W. Feng (1998): Semi-automated construction of the Louisiana coastline digital land/water boundary using Landsat Thematic Mapper satellite imagery (Department of Geography and Anthropology, Louisiana State University, Louisiana Applied Oil Spill Research and Development Program), OSRAPD Tech. Rep. Ser. 97-002.

CRACKNELL, A.P. (1999): Remote sensing techniques in estuaries and coastal zone-an update, Int. J. Remote Sensing, 19 (3), 485-496.

ERKKILA, A. and R. KAlliola (2004): Patterns and dynamic of coastal water in multi-temporal satellite images: support to water quality monitoring in the Arcipelago Sea, Finland, Estuarine Coastal Shelf Sci., 60 (2), 165167 . 
FraZier, P.S. and K.J. PAGe (2000): Water body detection and delineation with Landsat TM data, Photogramm. Eng. Remote Sensing, 66 (2), 1461-1467.

ISMES SpA (1987): Piano di Bacino Interregionale del Fiume Sinni, vol. 2, 107-109.

Kevin, W. and H.M. El Asmar (1999): Monitoring changing position of coastlines using thematic mapper imagery, an example from the Nile Delta, Geomorfology, 29, 93-105.

LILlESAND, T.M. and R.W. KIEFER (1987): Remote Sensing and Image Interpretation (John Wiley, Chichester), pp. 697.

Marsicano, D. and A. TrivisAni (1996): Metaponto una costa da salvare, Basilicata Regione Notizie, 1, 19-20.

MAstronUZZI, G. (1996): Il litorale settentrionale del golfo di Taranto: evoluzione morfologica e dinamica attuale, Basilicata Regione Notizie, 1, 27-32.

Millington, A.C., S.J. Walsh and P.E. Osborne (Editors) (2001): GIS and Remote Sensing Applications in Biogeography and Ecology (Kluwer Academic Publishers, Boston), pp. 344.

NAYAK, S. (2000): Critical issues in coastal zone management and role of remote sensing, in Subtle Issues in Coastal Management (Indian Institute of Remote Sensing, Dehradun), 77-98.

NOAA (1982): Computer applications to tides in the national ocean survey, supplement to the «Manual of Har- monic Analysis and Prediction of Tides», U.S. Department of Commerce, National Ocean Service (National Oceanic and Atmospheric Administration), Spec. Publ. No. 98 .

RYu, J.H., J.S. WON and K. Duck Min (2002): Waterline extraction from Landsat TM data in a tidal flat. A case study in Gomso Bay, Korea, Remote Sensing Environ., 83, 442-456.

San Miguel-Ayanz, J. and G.S. Biging (1997): Comparison of single-stage and multi-stage classification approaches for cover type mapping with TM and SPOT data, Remote Sensing Environ., 59, 92-104.

SiddiQui, M.N. and S. MAAJID (2004): Monitoring of geomorphological changes for planning reclamation work in coastal area of Karachi, Pakistan, Adv. Space Res., 33, 1200-1205.

Spilotro, G., M. Di Bratto, G. Cecilia and G. Leandro, (1999): Evoluzione recente del litorale alto Ionico compreso tra Foce Sinni e Foce Bradano (LaTIBI University of Basilicata), Final Report (on line http://www.latibi.unibas.it/prodotti/rapporti/17rapp01/).

Ustun, B., S. EKERCiN and N. MusAOGLU (2004): A performance analysis of the classification and manual digiting methods for the detection of coast line by using satellite image data, in Remote Sensing in Transition, edited by R. Goossens (Millpress, Rotterdam), 143148. 